\title{
Households Sociodemographic Profile as Predictors of Health Insurance Uptake and Service Utilization: A Cross-Sectional Study in a Municipality of Ghana
}

\author{
Eric Badu (D), ${ }^{1,2}$ Peter Agyei-Baffour, ${ }^{3}$ Isaac Ofori Acheampong, 4 \\ Maxwell Preprah Opoku, ${ }^{5}$ and Kwasi Addai-Donkor ${ }^{6}$ \\ ${ }^{1}$ Centre for Disability and Rehabilitation Studies, Kwame Nkrumah University of Science and Technology, Kumasi, Ghana \\ ${ }^{2}$ The University of Newcastle, Callaghan, NSW, Australia \\ ${ }^{3}$ Department of Health Policy, Management and Economics/School of Public Health, Kwame Nkrumah University of Science and \\ Technology (KNUST), Kumasi, Ghana \\ ${ }^{4}$ St. John of God Nursing Training College, Ministry of Health, Sefwi Asafo, Western Region, Ghana \\ ${ }^{5}$ University of Tasmania, Hobart, TAS, Australia \\ ${ }^{6}$ Ghana Health Service, Kwame Nkrumah University of Science and Technology, Kumasi, Ghana
}

Correspondence should be addressed to Eric Badu; badu3eric@gmail.com

Received 5 September 2017; Accepted 7 February 2018; Published 14 March 2018

Academic Editor: Carol J. Burns

Copyright ( $\odot 2018$ Eric Badu et al. This is an open access article distributed under the Creative Commons Attribution License, which permits unrestricted use, distribution, and reproduction in any medium, provided the original work is properly cited.

Introduction. Attempts to use health insurance in Low and Middle Income Countries (LMICs) are recognized as a powerful tool in achieving Universal Health Coverage (UHC). However, continuous enrolment onto health insurance schemes and utilization of healthcare in these countries remain problematic due to varying factors. Empirical evidence on the influence of household sociodemographic factors on enrolment and subsequent utilization of healthcare is rare. This paper sought to examine how household profile influences the National Health Insurance Scheme (NHIS) status and use of healthcare in a municipality of Ghana. Methods. A cross-sectional design with quantitative methods was conducted among a total of 380 respondents, selected through a multistage cluster sampling. Data were collected using a semistructured questionnaire. Data were analysed using descriptive and multiple logistics regression at 95\% CI using STATA 14. Results. Overall, 57.9\% of respondents were males, and average age was 34 years. Households' profiles such as age, gender, education, marital status, ethnicity, and religion were key predictors of NHIS active membership. Compared with other age groups, 38-47 years (AOR 0.06) and 58 years and above (AOR =0.01), widow, divorced families, Muslims, and minority ethnic groups were less likely to have NHIS active membership. However, females (AOR =3.92), married couples ( $\mathrm{AOR}=48.9)$, and people educated at tertiary level consistently had their NHIS active. Proximate factors such as education, marital status, place of residence, and NHIS status were predictors of healthcare utilization. Conclusion. The study concludes that households' proximate factors influence the uptake of NHIS policy and subsequent utilization of healthcare. Vulnerable population such as elderly, minority ethnic, and religious groups were less likely to renew their NHIS policy. The NHIS policy should revise the exemption bracket to wholly cover vulnerable groups such as minority ethnic and religious groups and elderly people at retiring age of 60 years.

\section{Introduction}

The burden of out-of-pocket payment (OOP) for health services cannot be underestimated. Out-of-pocket payment for health services continues to dominate in the health system of most countries especially those in low and middle income settings $[1,2]$. The global health statistics indicate that private health expenditure (PHE) in 2012 remained as high as 62.4\% in low income countries and $66 \%$ in lower middle income countries (LMICs) compared with $40.7 \%$ in higher income countries [1]. Again, out-of-pocket payment out of total PHE for this same period remained as high as $77.6 \%$ for low income 
countries and $86.7 \%$ for LMICs compared with $38.5 \%$ in high income countries. The high proportion of PHE demonstrates that the large global population continues to face financial burden to health services due to OOP [1].

Consequently, the World Health Organization (WHO) in 2005 responded to this by tasking member states to ensure universal health financing through the removal of OOP for health services [3]. The use of prepayment system is recognized as effective means to remove financial burden to health services especially among the poor and vulnerable population. Prepayment measures involving the use of health insurance has the ability to achieve universal health financing. This system of payment is a common practice among countries in the developing world. Countries, such as UK, Germany, France, Italy, Canada, and Australia, have employed different forms of prepayment system for health services $[4,5]$. There is evidence to support that most developed countries operate public and private health insurance as prepayment system of financing healthcare. In some settings, including Australia, Canada, Denmark, and Italy, the private health insurance operates as a complement to noncovered benefits and cost sharing as well as substitute for public insurance [5]. Across different settings, these insurance services are operated under guidance of central and regional government agencies [5].

Subsequently, countries in low and middle income settings are gradually closing the gap in addressing financial risk protection for the population. Several forms of prepayment systems including national health and private health insurance have been implemented in the last two decades [610]. There is again the emergence of social and communitybased insurance scheme, which usually forms part of a social protection programmes and policies. Many countries in Africa including Ghana, Nigeria, Tanzania Rwanda, Kenya, and Senegal as well as those in Asia are practicing a variety of social and community health insurance schemes which mobilize resources from the public and private sectors to finance healthcare $[2,11-13]$. This offers implementing countries the opportunity to expand financial access to the poorest populations. The use of varying types of health insurance is a strategy adopted by governments to establish compulsory schemes for public sector workers and establish equal scheme to cover workers in the informal sector simultaneously [14$16]$.

Ghana's response to universal health coverage (UHC) underscores the passage of the NHI bill into law in 2003 and subsequent operation in March 2005 [8, 17, 18]. The insurance was implemented to replace the previous "cashand-carry" system which allowed patients to pay at the point of receiving care. Similar to other developing countries [7], the health insurance had a primary objective to make healthcare affordable and increase the general utilization of drugs and healthcare particularly among the most vulnerable groups including those in the deprived areas $[19,20]$. There is evidence to support that the introduction of the insurance has increased out-patient utilization and subsequently increased out-patients per-capita $[17,19,20]$. Individuals who are insured against health risks are more likely to utilize outpatients care in public health facilities, especially in lower income communities $[19,21]$. These individuals enrolled in
NHIS have the greater chance of visiting clinics, obtain prescription, and seek formal healthcare $[19,22]$. Pregnant women, in particular, have the likelihood of utilizing prenatal care, give birth in a health facility without facing financial barriers, and again have skilled attendants present at birth [11, 23-25]. The free maternal health policy [15] has contributed to the increased uptake of antenatal care among these pregnant women.

Notwithstanding this, most households in Ghana continue to experience unmet needs to health services due to OOP at the health facility $[17,26]$. There has been inconsistency in the NHIS policy enrolment and renewal especially among households in rural and per-urban communities. The inability of these households to renew their subscription is attributed to varying factors at both health systems and individual levels. For instance, proximate factors such as unemployment [27], low level of income [28-30], limited education [27-29, 31], and individual's role within their families [27] discourage households from enrolling into the scheme. This apparently suggests that the health systems and sociodemographic factors of some households limit them from enrolling into the NHIS subscription, thereby preventing UHC. Subsequently, among the population who are able to register for the scheme, there has been inconsistency in renewal and utilization of healthcare. However, there is dearth of evidence that explores the influence of households' sociodemographic factors on NHIS active membership. This paper sought to examine how these factors influence active membership and subsequent utilization of health service among households in the Upper Denkyira East Municipality of Ghana. The evidence would inform NHIS policy decision, for instance, setting vulnerability exemption criteria for marginalized population.

Proximate Predictors of National Health Insurance Policy Uptake in Ghana. In Ghana, the sociodemographic information of households influences NHIS uptake. The sociodemographic information influences households' decision to enrol and renew their NHIS policy. These factors are mostly related to the social, economic, demographic, and health status of households [27-36]. Across different regional and geographic boundaries, social factor such as gender influences NHIS policy enrolment [27, 28, 30, 32, 34]. Past studies, for instance, have showed that females have more propensities to enrol and renew their NHIS policy compared with males [30, 31, 33]. Across different studies, females are $1.2-1.8$ times [30, 33] and 1.4-1.9 times [31, 34] more likely to enrol and renew their NHIS policy subscription, respectively. The increased participation of females in the NHIS policy is mostly linked to their motherly role and vulnerability to healthcare. Similarly, married individuals in Ghana stand higher odds of enrolling and renewing their NHIS policy [34, 35]. Those in their reproductive age, for instance, are about 1.3 times (95\% CI; $1.12,1.73)$ more likely to enrol into the NHIS policy compared with singles [35]. The increased participation of this group in the NHIS is attributed to their perception towards the cost of seeking care. This population is more susceptible to the burden of OOP of care and subsequently influences their increased participation in the NHIS policy. 
The religious affiliations of households have showed to influence their NHIS policy ownership. In some settings, including the Eastern and Central Regions of Ghana, previous studies have showed that households affiliated to some religion including Christianity, Islam, and Tradition were more likely to have NHIS active membership compared with those who were not affiliated to any religion [29, 31]. However, in a related study in the Upper West Region of Ghana, the increase in NHIS policy ownership according to religious affiliation varied based on gendered identity. For instance, males who were Muslims were more likely to have never enrol and to drop out of the NHIS policy compared with their Christian counterparts ( $\mathrm{OR}=2.6$ and $\mathrm{OR}=1.7$, resp.). However, females who belonged to Muslim and Traditional religion were more likely to have enrolled $(\mathrm{OR}=2.1$ and $\mathrm{OR}$ = 1.6) compared to their Christian counterparts [25]. This difference could be attributed to the fact that the Upper West Region is a Muslim dominated setting.

Furthermore, the age of household members has been extensively demonstrated as a predictor of NHIS policy ownership [28-30, 33, 35]. In several studies, the odds of enrolling and renewing NHIS policy increase with the age of household [27-29, 31]. Among different age groups, previous evidence showed that the elderly people of 60-70 years and above stand at greater odds of enrolling and renewing their NHIS policy. Across different studies, the elderly people of about 60-70 years and above are about 1.8-4.2 times (mean $=2.45$ ) more likely to enrol and renew their NHIS policy compared with those below this age category [29-33]. In the Eastern and Central regions of Ghana, for instance, the odds of enrolment into the NHIS among people in the richest quintile increase with the age; those aged 70 years and above were 13.6 times more likely to have NHIS active membership compared with the younger population [29]. The variation in NHIS policy ownership among different age categories further varies with vulnerability and gender identity. In some instances, vulnerable population including children and young women are more likely to own NHIS policy compared with other groups [30,37]. However, previous evidence has showed that, among women in their reproductive ages, those in their 45-49 years were 0.64 times less likely to enrol in the NHIS scheme compared with those below 45 years [35]. The age, vulnerability, and gender disparity to the NHIS policy ownership are directly linked to various exemptions reserved for some people including children, pregnant women, and aged and marginalized groups [17, 19]. Also, the size of individual households predicts their NHIS policy ownership. The odds of enrolling and renewing NHIS policy decreases with household size [28, 32]. In a previous study, individuals with a larger household size, for instance, 12 and above (AOR $=0.33 ; 95 \% \mathrm{CI} ; 0.24,0.45)$ were less likely to enrol in the NHIS scheme [32]. The burden of enrolling and renewing the NHIS policy could be challenging for individuals with a higher household size. This could be attributed to the increased charge or one-off payment for clients, especially if they are not well resourced.

In the Ghanaian setting, the ability of households to enrol and renew their NHIS policy is associated with the wealth quintiles mostly linked to income. It is previously reported that households with higher socioeconomic status have higher odds to enrol and renew their NHIS policy compared with those in poor socioeconomic standings [2830]. The odds of enrolling and renewing NHIS policy among households in the highest socioeconomic status vary, ranging from about 1.6 to 4.1 times, higher than those in the lowest socioeconomic groups $[27,30]$. This difference further varies by gender and age groups. In a previous study, for instance, the poorest males were 3.4 times less likely to enrol into the NHIS policy compared to their rich counterparts [25]. In the same instance, females in the poorest category were 3.8 times more likely to have never enrolled in the NHIS compared with those in the richest group [25]. Previous studies have again showed that, among women in their reproductive age, those in the richer $(\mathrm{OR}=1.7 ; 95 \% \mathrm{CI} ; 1.2,2.3)$ and richest wealth quintile $(\mathrm{OR}=1.4 ; 95 \% 0.98,2.11)$ were more likely to enrol in the NHIS policy [35]. Similarly, across different age groups, older people in the third $(\mathrm{OR}=2.5 ; 95 \% \mathrm{CI} ; 1.0,6.0)$ and fourth wealth quintile $(\mathrm{OR}=3.8 ; 95 \% \mathrm{CI} ; 1.5,9.4)$ were more likely to enrol in the NHIS policy compared to other groups [36]. This demonstrates that the variation in NHIS policy ownership among the poor and rich further differs according to different sociodemographic information such as gender and age.

Across different settings, the increase in the education level of households increases the odds of enrolling and renewing NHIS policy [27-29, 31]. It is previously reported that individuals educated at higher level, preferably tertiary, have higher odds of enrolling and renewing their NHIS policy. The increase in the odds of enrolling and renewing NHIS among households educated at tertiary level varies, ranging from about 2.1 to 5.9 times more higher than those with lower or no education [27, 28, 31]. Similarly, the increased odds of enrolling and renewing NHIS policy among educated households vary depending on the wealth quintiles. In a previous study, for instance, the odds of enrolling in the NHIS policy among clients educated at tertiary level increase from 29 for individuals in the first poorest quintile compared with 9.12 and 2.4 for the third and fourth quintile, respectively [29]. Again, the influences of educational attainment on NHIS policy ownership varies depending on the gender identify. Previous study on the Upper West Region of Ghana showed that males with primary or no education were more likely to have never enrolled $(\mathrm{OR}=4.9$ and $\mathrm{OR}=6.9$, resp.) and to drop out $(\mathrm{OR}=4.8$ and $\mathrm{OR}=3.3$, resp. $)$ compared with university/college education [25]. Similarly, females with primary or no education had higher odds of never enrolled $(\mathrm{OR}=12.8$ and $\mathrm{OR}=23.9$, resp. $)$ and drop out $(\mathrm{OR}=1.6$ and 2.06) compared with those educated at tertiary level [25].

Additionally, the health status of individuals influences their decision to continuously enrol and renew their NHIS policy. In previous studies, individuals with poor health status were about 1.13-1.9 times more likely to have NHIS active membership compared with those in good health $[31,34]$. For instance, individuals with self-reported chronic conditions [30] and hospitalised [36] were about 1.9-2.2 times and 4.4 times, respectively, are more likely to enrol in NHIS scheme compared with those with no such conditions. The increased participation of people with chronic health 
condition especially the older population in the NHIS policy could be attributed to frequent healthcare needs. People who have poor health condition are at greater risk of experiencing health complications, which require immediate healthcare needs.

The responsible person to head a family influences their ability to enrol and renew their NHIS policy. Households headed by a male have showed to have increased odds (OR $=2.5 ; 95 \% \mathrm{CI} ; 1.2,5.1)$ of enrolling and renewing their NHIS policy. The employment status of these household heads influences their economic ability to enrol and renew the NHIS policy. In instances where the individual household heads are engaged in a formal sector employment, they stand a higher propensity $(\mathrm{OR}=3.7)$ to enrol and renew their NHIS policy [27].

\section{Methods}

2.1. Study Site. The study was conducted in the Upper Denkyira East Municipality. The Municipality covers a total land area of 1,700 square kilometers, which is about $17 \%$ of total land of Central Region, one of the four most deprived regions in Ghana. The municipality accommodates an estimated population of 79,793 people in 2013 [38]. Children under one year constitute 2,502 people whereas children under 5 years constitute 15,636 as of 2013. The municipality has 22 health facilities, including 17 public and 5 private facilities as of 2013 [38]. There were a total of 12 functional CHIP zones in the municipality in 2013 [38]. Social services such as schools and health facilities are located around the urban settings leaving the vast rural areas underserved and underdeveloped. The major economic activities are peasant farming and small scale alluvium mining along the basin of Ofin River. The municipality is known as one of the settings with poor health outcomes due to weakness in the municipal health systems and again ranked low on all poverty and economic indicators. The road network is poor with some portions unmotorable during the rainy season. There is also long distance to health centers and again high transport cost to service delivery centers. These weaknesses present unbearable challenges to the population in meeting their health service needs.

2.2. Study Design. The study used a cross-sectional design with quantitative methods of data collection. The design was used to collect data from all prospective respondents over three-month period (3 months, February, 2015-April, 2015). The cross-sectional design is relevant to measure the sociodemographic predictors of NHIS active membership and healthcare utilization. This was applicable as the researchers aimed to examine factors that influence active membership and service utilization. The quantitative data helped to make inferences about the situation of NHIS active membership within the municipality.

2.3. Sample Size and Sampling. The sample size was estimated using Cochran's $[39,40]$ sample size formula $\left(n_{0}=\left(Z^{2} *\right.\right.$ $(p)(q)) / d^{2}$ ), where $z$ value $=1.96$ or $95 \%$ confidence level, $p=$ proportion of population enrolled in NHIS, $d=$ degree of freedom, and $q=1-p$ ). A proportion of $33 \%$ clients enrolled in the NHIS in the Upper Denkyira Municipality [38] was used to estimate the sample size. The formulae use a " $z$ value" of 1.96 or $95 \%$ confidence, significance level of 0.05 , and degree of freedom of 0.05 . The first stage of the calculation arrived at 339.75, approximate of 340 respondents. The calculation further allowed a $10 \%$ nonresponse rate and design effects of 1.06 to arrive at 380 respondents.

The households for the study were identified through a multistage cluster and simple random sampling approaches. The first stage sampling identified communities in the Upper Denkyira Municipality. The communities sampled were Zongo, Dunkwa-Soro, Atechem, Mfuom, Kadadwen, and Compound [38]. The selected communities had a health center or clinic that accepts clients using NHIS. The second stage used simple random sampling to select households in each of the communities. In all, a maximum of 380 households were enrolled into the study. The researchers zoned the principal streets in each of the communities as initial point before moving from house to house. Numerical order of house numbers was used as a sampling frame. In each of the household visited, the study enrolled the head of the household as the respondent. All the heads of the households that were approached during the study were made to pick from a paper with an inscription "Yes" and "No" and all those who picked "Yes" and consented to participate (92\%) were enrolled as respondents. This approach was repeated until the sample size of 380 households was reached. In all, less than $10 \%$ of prospective respondents answered "No." Again, in instances, where none of the household members met the inclusion criteria, the research team moved to the next household. Household in this context was operationally defined as individual or a group of people who live together in the same house or compound and share the same house-keeping arrangements [41] and depend on a common source of income for subsistence.

2.4. Data Collection. Data were obtained from respondents through administration of structured questions on face-toface basis. Questions that were presented to the respondents were related to the sociodemographic information, current status of NHIS, and access and use of healthcare. The sociodemographic variables included gender, age, marital status, highest education, years of schooling, and religion. Questions on NHIS were related to the current status of clients on the scheme.

2.5. Data Analysis. The study used descriptive and inferential statistics to present results. The analysis first computed percentage distribution of the household profile of respondents. These frequencies and percentage distribution were grouped according to the type of variable-continuous and categorical. The continuous variables were age, monthly income, household size, and the number of dependents. The categorical variables were gender, education, marital status, occupation, place of residence, ethnic background, religion, NHIS status, and healthcare utilization. The analysis further used bivariate and multivariate logistics regression to examine the influence of sociodemographic factors on NHIS 
active membership. Odds ratio (OR) and adjusted odds ratio (AOR) were used to report the strength of influence of the sociodemographic factors on NHIS active membership. The main outcome variable for the analysis was the current NHIS status of respondents. Healthcare utilization was measured using individuals who had visited the health facility for care with the health insurance in the last twelve (12) months. The analysis was presented at 95\% significance level at $\alpha=0.01, \alpha$ $=0.03$, and $\alpha=0.05$. The analyses set the reference group for both OR (odds ratio) and AOR (adjusted odds ratio) as 1.0. All statistical analyses were estimated using STATA version (14).

\section{Results}

3.1. Sociodemographic Characteristics of Respondents. A total of 380 respondents were recruited for the study. The average age of respondents was 34 years, and about $47.1 \%$ were between 18 and 27 years. Males (57.9\%) dominated females in the study. More than a third (46.9\%) of respondents had tertiary level education, whilst less than a fifth each had secondary, primary, and no formal education (Table 1). A little above half, $52.4 \%$, were singles whilst more than one-third (36.5\%) described their marital status as married.

More than a third of respondents (43.75\%) were engaged in semiskilled employment, $36.9 \%$ as skilled workers, and $19.29 \%$ were not engaged in any employment. A little over a third, $34.4 \%$, of respondents disclosed their places of residence as old town, $25.47 \%$ as peri-urban, and $18.16 \%$ as Zongo (literally means in Hausa dialect, "temporal abode," a suburb in a community where Muslims and other people from the savannah region live). As high as 7 in 10 and 6 in 10 said yes to use of NHIS and healthcare, respectively.

The median and average monthly income of respondents were GHC 200 (USD 52.35) (using 2016 exchange rate of GHC 3.82 = 1 USD equivalent) and GHC 412.94 (USD 108.12), respectively (Table 1). The mean household size was 5 persons per household. Average number of dependents was 3 persons and minimum and maximum was 1 and 12 persons, respectively. Most respondents, $80 \%$ and $53.9 \%$, respectively, had Christian religious and Denkyira ethnic background.

3.2. The Influence of Sociodemographic Factors on NHIS Uptake. Table 2 presents the influence of sociodemographic factors on NHIS status. Sociodemographic factors such as age, monthly income, household size, gender, marital status, education, employment, place of resident, and religion influence the NHIS status of households in the crude odds ratio. The odds of renewing NHIS policy increased with the age of respondents. Households members within the age group of 28-37 years $(\mathrm{OR}=3.15 ; 95 \% \mathrm{CI} ; 1.88,5.29)$, 38-47 years $(\mathrm{OR}=2.41 ; 95 \% \mathrm{CI} ; 1.37,4.24), 48-57$ years $(\mathrm{OR}=3.13 ; 1.40$, $6.93)$, and $58+(\mathrm{OR}=3.0 ; 95 \% 1.27,7.05)$ were more likely to renew their NHIS policy compared with those below 27 years. Similarly, females $(95 \%$ CI $0.98,2.61)$ and individuals who were married $(\mathrm{OR}=4.27 ; 95 \% \mathrm{CI} ; 2.78,6.54)$ were more likely to have their NHIS status active compared with males and singles, respectively.
TABLE 1: Sociodemographic characteristics of respondents.

\begin{tabular}{|c|c|c|}
\hline Variable & Frequency & Percentage (\%) \\
\hline \multicolumn{3}{|l|}{ Continuous variable } \\
\hline \multicolumn{3}{|l|}{ Age } \\
\hline $18-27$ & 179 & 47.11 \\
\hline $28-37$ & 80 & 21.05 \\
\hline $38-47$ & 60 & 15.79 \\
\hline $48-57$ & 33 & 8.68 \\
\hline $58+$ & 28 & 7.37 \\
\hline $\begin{array}{l}\text { Median; mean (SD); } \\
\text { Min/Max }\end{array}$ & $28.5 ; 34(13.96)$ & \\
\hline \multicolumn{3}{|l|}{ Monthly income $(\mathrm{GHC})^{1}$} \\
\hline$>200$ & 130 & 51.18 \\
\hline $200-500$ & 45 & 17.72 \\
\hline $500-1000$ & 64 & 25.20 \\
\hline $1000-1500$ & 9 & 3.54 \\
\hline $1500+$ & 6 & 2.36 \\
\hline $\begin{array}{l}\text { Median; mean (SD); } \\
\text { Min/Max }\end{array}$ & $\begin{array}{c}200 ; 412.94(417.55) ; \\
10 / 2000\end{array}$ & \\
\hline \multicolumn{3}{|l|}{ Household size } \\
\hline $1-3$ & 64 & 17.07 \\
\hline $4-6$ & 195 & 52.00 \\
\hline $7-9$ & 116 & 30.93 \\
\hline Mean (SD); Min/Max & 5.3 (1.93); $1 / 9$ & \\
\hline \multicolumn{3}{|l|}{ Number of dependents } \\
\hline $1-3$ & 147 & 61.51 \\
\hline $4-6$ & 70 & 29.29 \\
\hline $7-9$ & 13 & 5.44 \\
\hline $10+$ & 9 & 3.77 \\
\hline Mean (SD); Min/Max & $3.4(2.3) ; 1 / 12$ & \\
\hline \multicolumn{3}{|l|}{ Categorical variable } \\
\hline \multicolumn{3}{|l|}{ Gender } \\
\hline Male & 219 & 57.94 \\
\hline Female & 159 & 42.06 \\
\hline \multicolumn{3}{|l|}{ Education } \\
\hline No formal education & 49 & 12.93 \\
\hline Primary & 59 & 15.57 \\
\hline Secondary & 79 & 20.84 \\
\hline Tertiary & 178 & 46.97 \\
\hline Other & 14 & 3.69 \\
\hline \multicolumn{3}{|l|}{ Marital status } \\
\hline Single & 199 & 52.37 \\
\hline Married & 139 & 36.58 \\
\hline Divorce & 27 & 7.11 \\
\hline Widow & 15 & 3.95 \\
\hline \multicolumn{3}{|l|}{ Occupation } \\
\hline Skilled & 136 & 36.96 \\
\hline Semiskilled & 161 & 43.75 \\
\hline Unemployed & 71 & 19.29 \\
\hline \multicolumn{3}{|l|}{ Place of residence } \\
\hline Slum & 22 & 5.33 \\
\hline Zongo & 67 & 18.16 \\
\hline Old Town & 127 & 34.42 \\
\hline Peri-Urban & 94 & 25.47 \\
\hline New-Site & 59 & 15.99 \\
\hline \multicolumn{3}{|l|}{ Ethnic background } \\
\hline Denkyira & 185 & 53.94 \\
\hline Other & 158 & 46.06 \\
\hline \multicolumn{3}{|l|}{ Religion } \\
\hline Christianity & 296 & 80.00 \\
\hline
\end{tabular}


TABle 1: Continued.

\begin{tabular}{lcc}
\hline Variable & Frequency & Percentage (\%) \\
\hline Islam & 74 & 20.00 \\
NHIS active & & \\
Yes & 277 & 74.26 \\
No & 96 & 25.74 \\
Use of Healthcare & & \\
Yes & 215 & 63.61 \\
No & 123 & 36.39 \\
\hline
\end{tabular}

${ }^{1}$ GHC 3.82 = USD 1, exchange rates from May 4, 2016.

The odds of enrolling and renewing NHIS subscription increased with the level of education. Individuals who had some educational credentials up to primary $(\mathrm{OR}=2.22 ; 95 \%$ CI; 1.27, 3.87), secondary (OR $=2.71 ; 95 \% \mathrm{CI} ; 1.65,4.47)$, and tertiary level $(\mathrm{OR}=4.0 ; 95 \% \mathrm{CI} ; 2.76,5.79)$ were more likely to have NHIS active membership compared with those with no education. Again, there was increase in the trends of the odds of using NHIS with the sector of employment. Individuals with public sector employment $(\mathrm{OR}=4.5 ; 95 \% \mathrm{CI} ; 2.09,9.68)$, Trading (OR $=3.0 ; 95 \% \mathrm{CI} ; 1.60,5.61)$, and self-employment $(\mathrm{OR}=4.70 ; 95 \% \mathrm{CI} ; 2.37,9.30)$ were more likely to have active membership compared with those with no employment. Individuals who described their residency as New sites and peri-urban were 2.57 and 5.33 times, respectively, more likely to have their NHIS active compared with those who described their residence as Slums.

The income level of respondents increases the odds of enrolling and renewing NHIS policy. Individuals who earned above GHC 500-GHC 1000 (OR = 5.3; 95\% CI; 2.69, 10.41) and $200-500(\mathrm{OR}=2.63 ; 95 \% \mathrm{CI} ; 1.37,5.17)$ were more likely to have their NHIS active compared with those who earned below GHC 200 (USD 52.37). Individuals who had more than 4-6 household size were 2.82 times more likely to have their NHIS status active compared with those who had less 1-3 household size. Individuals who mentioned their religious affiliation as Islam were 0.47 times $(95 \% \mathrm{CI}$; $0.27,0.80)$ less likely to have their NHIS status active.

Sociodemographic factors such as age, gender, marital status, education, ethnicity, and education consistently increased the odds of having active membership in the NHIS after the inclusion of other co-covariates. Individuals who were 38-47 years (AOR 0.06) and 58 years and above (AOR $=0.01$ ) were, respectively, less likely to have their NHIS active after adjusting for other covariates. Consistently, being a female had a higher likelihood of having NHIS status as active $\mathrm{AOR}=3.92(95 \% \mathrm{CI} ; 1.21,12.67)$ after accounting for the effect of other confounding variables. Different educational levels were consistently associated with active NHIS status after adjusting for other covariates. Respondents who were married consistently had higher odds (AOR $=48.9)$ of having their NHIS status active after adjusting for other covariates. Similar to the univariate analysis, the odds of having NHIS status active decreased with religious background; those with Islam religious background were less likely to have their NHIS active at AOR 0.12 (95\% CI; 0.03, 0.52) compared with Christians after accounting for other covariates.
3.3. The Influence of Households' Profile on Healthcare Utilization. Table 3 presents the influence of households profile on healthcare utilization within the Upper Denkyira Municipality. Females were 1.16 times (95\% CI; 0.14, 1.61) more likely to utilize healthcare compared with males. Respondents who had tertiary level education were 2.44 times (95\% CI; 1.20, 4.97) more likely to use healthcare compared with those who reported no formal education. There was an increased odd of using healthcare with the marital status of respondents; those who reported as married as well as widow, respectively, were 1.47 times (95\% CI; 1.00, 2.16) and 12.99 times (95\% CI; 1.70, 99.37) more likely to use healthcare compared with those who were single. There was again increase in trends of the odds of using healthcare with employment; those who described their employment status as self-employed were 4.00 (95\% CI; 2.06, 7.74) times more likely to use healthcare compared with those with no employment. The analysis further showed that the use of healthcare was associated with the monthly income of the respondents; those who earn more than GHC 200 (USD 52.37) and above were 2 times (95\% CI; 1.09, 3.64) more likely to use healthcare compared with those who earn below GHC 200 (USD 52.37). Respondents who described their residency as peri-urban were 3.2 times more likely to use healthcare compared with those who lived in Slums.

Consistently, having tertiary level education had a higher likelihood of using healthcare AOR $=6.46$ (95\% CI; 0.89, 46.41) after accounting for the addition of other covariates like age, gender, and marital status. Also, respondents who were married and widowed consistently had higher odds $(\mathrm{AOR}=10.32 ; \mathrm{AOR}=20.49)$ of using healthcare after adjusting for other covariates. Also, the place of residency of respondents was consistently associated with the use of healthcare after adjusting for the inclusion of other covariates.

\section{Discussion}

The study was conducted to examine households' profile that predicts NHIS active membership and subsequent utilization of healthcare in the Upper Denkyira East Municipality. The household profiles were categorized according to sociocultural, social class, economics, and spatial or geographical location.

The median and average ages of household members were 28.5 years and 34 years, respectively. The age characteristics demonstrate an active adult population in the study setting. This category of the population has the ability to contribute to the active labour force in both formal and informal sector. The trend of age distribution presents an inverse relationship between population growth and aging; an increase in the ages of the population presents a decreased population. The finding confirms similar trend of age distribution in the 2010 national population census [41]. The national population census presented an increased adult population with a decreasing aging population. Again, the study showed that more than $50 \%$ of households each constitute males and singles. The marital status of the population confirms the general characteristic of the Ghanaian population. In the recent population and housing census, singles were more dominant than married individuals [41]. However, the gender 
TABLE 2: Logistic regression analysis of households' profile and NHIS uptake.

\begin{tabular}{|c|c|c|c|c|c|c|}
\hline \multirow{2}{*}{ Variable } & \multicolumn{6}{|c|}{ NHIS active membership } \\
\hline & Model 1 OR & $95 \% \mathrm{CI}$ & $p$ value & Model 2 AOR & $95 \% \mathrm{CI}$ & $p$ value \\
\hline \multicolumn{7}{|l|}{ Continuous variable } \\
\hline \multicolumn{7}{|l|}{ Age } \\
\hline $18-27$ & 1.00 & & & 1.00 & & \\
\hline $28-37$ & 3.15 & $1.88,5.29$ & 0.01 & 0.47 & $0.06,3.51$ & 0.46 \\
\hline $38-47$ & 2.41 & $1.37,4.24$ & 0.01 & 0.06 & $0.00,0.77$ & 0.05 \\
\hline $48-57$ & 3.13 & $1.40,6.93$ & 0.05 & 0.24 & $0.02,3.19$ & 0.28 \\
\hline $58+$ & 3.00 & $1.27,7.05$ & 0.01 & 0.01 & $0.00,0.25$ & 0.01 \\
\hline \multicolumn{7}{|c|}{ Monthly income $(\mathrm{GHC})^{1}$} \\
\hline Below 200 & 1.0 & & & 1.00 & & \\
\hline $200-500$ & 2.67 & $1.37,5.17$ & 0.01 & 0.96 & $0.17,5.35$ & 0.96 \\
\hline $500-1000$ & 5.3 & $2.69,10.41$ & 0.01 & 1.06 & $0.26,4.36$ & 0.92 \\
\hline $1000-1500$ & 3.5 & $0.72,16.8$ & 0.11 & 0.12 & $0.01,1.47$ & \\
\hline $1500+$ & 0.5 & $0.09,2.72$ & 0.42 & 0.23 & $0.02,3.53$ & \\
\hline \multicolumn{7}{|l|}{ Household size } \\
\hline $1-3$ & 1.0 & & & 1.0 & & \\
\hline $4-6$ & 2.82 & $2.04,3.89$ & 0.01 & 0.28 & $0.04,1.64$ & 0.16 \\
\hline $7-9$ & 3.07 & $2.00,4.70$ & 0.01 & 0.81 & $0.10,6.35$ & 0.84 \\
\hline \multicolumn{7}{|l|}{ Number of dependents } \\
\hline $1-3$ & 1.0 & & & 1.0 & & \\
\hline $4-6$ & 1.07 & $0.55,2.10$ & 0.84 & 3.83 & $0.93,15.75$ & 0.06 \\
\hline $7-9$ & 0.64 & $0.18,2.24$ & 0.48 & 2.84 & $0.17,45.95$ & 0.46 \\
\hline $10+$ & 2.54 & $0.31,21.06$ & 0.39 & 3.30 & $0.07,155.4$ & 0.54 \\
\hline \multicolumn{7}{|l|}{ Categorical variables } \\
\hline \multicolumn{7}{|l|}{ Gender } \\
\hline Male & 1.0 & & & 1.0 & & \\
\hline Female & 3.86 & $0.98,2.61$ & 0.00 & 3.92 & $1.21,12.67$ & 0.05 \\
\hline \multicolumn{7}{|l|}{ Marital status } \\
\hline Single & 1.0 & & & 1.0 & & \\
\hline Married & 4.27 & $2.78,6.54$ & 0.00 & 48.9 & $4.46,537$ & 0.01 \\
\hline Divorce & 2.0 & $0.89,4.45$ & 0.09 & 97.0 & $5.54,1697$ & 0.01 \\
\hline Widow & 6.5 & $1.46,28.80$ & 0.14 & 2683 & $32.20,2235$ & 0.01 \\
\hline \multicolumn{7}{|l|}{ Education } \\
\hline No formal education & 1.0 & & & 1.0 & & \\
\hline Primary & 2.22 & $1.27,3.87$ & 0.01 & 9.87 & $1.52,64.07$ & 0.05 \\
\hline Secondary & 2.71 & $1.65,4.47$ & 0.00 & 7.80 & $1.24,49.10$ & 0.03 \\
\hline Tertiary & 4.0 & $2.76,5.79$ & 0.00 & 9.68 & $1.00,92.92$ & 0.05 \\
\hline Other & 1.8 & $0.60,5.37$ & 0.29 & 15.31 & $0.58,402.7$ & 0.10 \\
\hline \multicolumn{7}{|l|}{ Occupation } \\
\hline None & 1.00 & & & 1.0 & & \\
\hline Public sector & 4.50 & $2.09,9.68$ & 0.01 & 1.85 & $0.14,23.52$ & 0.63 \\
\hline Farming & 1.88 & $1.04,3.38$ & 0.01 & 0.69 & $0.05,9.72$ & 0.79 \\
\hline Trading & 3.00 & $1.60,5.61$ & 0.01 & 1.38 & $0.09,20.07$ & 0.81 \\
\hline Apprenticeship & 2.50 & $0.96,6.44$ & 0.06 & 2.66 & $0.09,74.81$ & 0.56 \\
\hline Self-employed & 4.70 & $2.37,9.30$ & 0.01 & 1.77 & $0.08,35.44$ & 0.70 \\
\hline Other & 3.31 & $1.89,5.79$ & 0.01 & 7.41 & $0.24,220.6$ & 0.24 \\
\hline
\end{tabular}


TABLE 2: Continued.

\begin{tabular}{|c|c|c|c|c|c|c|}
\hline \multirow{2}{*}{ Variable } & \multicolumn{6}{|c|}{ NHIS active membership } \\
\hline & Model 1 OR & $95 \% \mathrm{CI}$ & $p$ value & Model 2 AOR & $95 \% \mathrm{CI}$ & $p$ value \\
\hline \multicolumn{7}{|c|}{ Place of residence } \\
\hline Slum & 1.00 & & & 1.0 & & \\
\hline Zongo & 2.67 & $1.55,4.58$ & 0.01 & 5.04 & $0.46,55.38$ & 0.18 \\
\hline Old Town & 3.37 & $2.39,5.88$ & 0.01 & 3.57 & $0.41,30.56$ & 0.24 \\
\hline New site & 2.57 & $1.63,4.05$ & 0.01 & 7.07 & $0.49,102.1$ & 0.15 \\
\hline Peri-urban & 5.33 & $2.61,10.86$ & 0.01 & 1.92 & $0.16,22.77$ & 0.60 \\
\hline Other & 1.5 & $0.42,5.31$ & 0.53 & 1 & & \\
\hline \multicolumn{7}{|c|}{ Ethnic background } \\
\hline Denkyira & 1.00 & & & 1.0 & & \\
\hline Other & 0.69 & $0.41,1.13$ & 0.14 & 0.17 & $0.03,0.78$ & 0.01 \\
\hline \multicolumn{7}{|l|}{ Religion } \\
\hline Christianity & 1.0 & & & 1.0 & & \\
\hline Islam & 0.47 & $0.27,0.80$ & 0.01 & 0.12 & $0.03,0.52$ & 0.01 \\
\hline
\end{tabular}

${ }^{1}$ GHC 3.82 = USD 1, exchange rates from May 4, 2016; OR = odds ratio; AOR = adjusted odds ratio; CI = confidence interval; Outcome measures: NHIS uptake; significance level: $\alpha=0.01, \alpha=0.03$, and $\alpha=0.05$; OR and AOR for reference group were set as 1.0.

disparity contradicts the national dynamics. In the Ghanaian population, females generally have a higher ratio compared with men-1:6 according 2010 housing and population census [41].

The study showed that the median and average monthly incomes of households were GHC 200 (USD 52.35) and GHC 412.94 (USD 108.12), respectively. The average monthly income in particular was about 1.9 times higher than 2015 national monthly minimum wage of GHC 210 (USD 54.97) [42]. The rate suggests that households were relatively earning higher from their respective employment. This finding implies that the household members were relatively betteroff when compared with the national standard. However, this may not translate to the actual standard of living among households in real terms. The households' welfare and standard of living could also be influenced by the size of individual household members. The average household size of 5 members could imply significant economic burden on the families especially when compared with the relative monthly income.

The study showed that $74 \%$ of household members were insured under the NHIS. This finding implies that most households were using the NHIS as their primary source of seeking healthcare. This number is about 2 times higher than the 2012 and 2013 national level active membership which stands at $37 \%$ and $38 \%$, respectively. Again, the $74 \%$ insured clients were about 1.2 times higher than a similar study in Barekese district in the Ashanti Region of Ghana [28, 32]. The high rate of active policy membership may help to reduce the burden associated with out-of-pocket payment for healthcare. The discussion demonstrates that, across different districts of Ghana, active membership of NHIS differs. The variation in active policy ownership across different districts and regions could be attributed to varying factors, which may include individual sociodemographic factors.
The households profile such as age, gender, education, marital status, and ethnic and religious background influenced the NHIS active membership. These factors significantly influenced NHIS status, either likely increase or reduce active membership. The marital status of household members significantly influenced NHIS active membership. Married household members were more likely to have their NHIS active compared with singles. This finding could be attributed to the fact that married couples might fear the burden of outof-pocket payment of healthcare particularly when there is a dependant. This finding confirms earlier studies in Ghana, which found that married individuals have higher odds of enrolling and renewing NHIS policy $[34,35]$. This argument demonstrates that across different settings of Ghana, people who are married stand a higher chance of enrolling and renewing their NHIS policy. This demonstrates their continuous search for financial risk protection to healthcare.

In this study, females were more likely to have active NHIS policy. This finding could be attributed to the differences in health seeking behaviour between females and males. Females seem more responsive to sickness and will report promptly to health facilities than men who would usually wait till their condition deteriorates due to masculinity. Again, females are perceived as vulnerable especially during pregnancy and more prone to seeking care at the health facility. This may probably influence their decision to continually enrol and renew NHIS policy. This could also be linked to the free maternal health policy that grants exemption to payment of NHIS among pregnant women. This finding corroborate with previous studies across different settings of Ghana [30, $31,33-35]$. In a previous finding, females had increased odds of enrolling and renewing their NHIS policy compared with males. For instance, married women in their reproductive ages have demonstrated to be at greater odds in enrolling and renewing their NHIS policy [35]. The discussion has 
TABLE 3: Logistic regression analysis of households' profile and healthcare utilization.

\begin{tabular}{|c|c|c|c|c|c|c|}
\hline \multirow{2}{*}{ Variable } & \multicolumn{6}{|c|}{ Use of healthcare with NHIS } \\
\hline & Model 1 OR & $95 \% \mathrm{CI}$ & $p$ value & Model 2 AOR & $95 \% \mathrm{CI}$ & $p$ value \\
\hline \multicolumn{7}{|l|}{ Continuous variable } \\
\hline \multicolumn{7}{|l|}{ Age } \\
\hline $18-27$ & 1.00 & & & 1.00 & & \\
\hline $28-37$ & 0.64 & $0.34,1.18$ & 0.15 & 0.51 & $0.05,4.95$ & 0.56 \\
\hline $38-47$ & 0.39 & $0.18,0.84$ & 0.05 & 0.18 & $0.12,2.73$ & 0.22 \\
\hline $48-57$ & 0.84 & $0.31,2.23$ & 0.73 & 0.28 & $0.02,2.86$ & 0.34 \\
\hline $58+$ & 2.81 & $0.79,9.95$ & 0.10 & 12.53 & $0.31,493.09$ & 0.17 \\
\hline \multicolumn{7}{|c|}{ Monthly income $(\mathrm{GHC})^{1}$} \\
\hline Below 200 & 1.00 & & & 1.00 & & \\
\hline $200-500$ & 2.00 & $1.09,3.64$ & 0.01 & 1.37 & $0.29,8.49$ & 0.39 \\
\hline $500-1000$ & 1.10 & $0.66,1.82$ & 0.70 & 0.39 & $0.07,2.20$ & 0.29 \\
\hline $1000-1500$ & 2.25 & $0.69,7.30$ & 0.17 & 1.01 & $0.04,21.07$ & 0.99 \\
\hline $1500+$ & 2.5 & $0.48,12.88$ & 0.27 & 1.00 & - & \\
\hline \multicolumn{7}{|l|}{ Household size } \\
\hline $1-3$ & 1.00 & & & 1.00 & & \\
\hline $4-6$ & 0.72 & $0.38,1.37$ & 0.38 & 1.20 & $0.31,4.39$ & 0.78 \\
\hline $7-9$ & 0.65 & $0.32,1.32$ & 0.24 & 0.23 & $0.04,1.36$ & 0.11 \\
\hline \multicolumn{7}{|l|}{ Number of dependents } \\
\hline $1-3$ & 1.00 & & & 1.00 & & \\
\hline $4-6$ & 0.82 & $0.43,1.53$ & 0.53 & 0.73 & $0.20,2.64$ & 0.63 \\
\hline $7-9$ & 1.40 & $0.34,5.68$ & 0.63 & 0,09 & $0.003,2.92$ & 0.18 \\
\hline $10+$ & 1.00 & $0.22,4.38$ & 1.00 & 2.85 & $0.03,162.01$ & 0.61 \\
\hline \multicolumn{7}{|l|}{ Gender } \\
\hline Male & 1.00 & & & 1.00 & & \\
\hline Female & 1.16 & $1.17,2.35$ & 0.01 & 0.48 & $0.14,1.61$ & 0.23 \\
\hline \multicolumn{7}{|l|}{ Education } \\
\hline No formal education & 1.00 & & & 1.00 & & \\
\hline Primary & 1.76 & $0.73,4.27$ & 0.19 & 1.00 & & \\
\hline Secondary & 1.82 & $0.82,4.02$ & 0.13 & 2.39 & $0.44,12.80$ & 0.30 \\
\hline Tertiary & 2.44 & $1.20,4.97$ & 0.01 & 6.46 & $0.89,46.41$ & 0.05 \\
\hline Other & 0.95 & $0.17,5.28$ & 0.95 & 4.92 & $0.63,37.98$ & 0.12 \\
\hline \multicolumn{7}{|l|}{ Marital status } \\
\hline Single & 1.00 & & & 1.00 & & \\
\hline Married & 1.47 & $1.00,2.16$ & 0.05 & 10.32 & $1.24,85.94$ & 0.05 \\
\hline Divorce & 1.66 & $0.72,3.80$ & 0.22 & 6.89 & $0.86,129.89$ & 0.19 \\
\hline Widow & 12.99 & $1.70,99.37$ & 0.01 & 20.49 & $0.63,37.98$ & 0.05 \\
\hline \multicolumn{7}{|l|}{ Occupation } \\
\hline None & 1.00 & & & 1.00 & & \\
\hline Public sector & 1.13 & $0.64,1.98$ & 0.66 & 0.42 & $0.04,4.23$ & 0.46 \\
\hline Farming & 1.40 & $0.72,2.71$ & 0.32 & 1.20 & $0.09,14.76$ & 0.88 \\
\hline Trading & 1.18 & $0.66,2.08$ & 0.56 & 0.47 & $0.03,5.86$ & 0.56 \\
\hline Apprenticeship & 1.22 & $0.50,2.94$ & 0.65 & 3.24 & $0.18,78.29$ & 0.46 \\
\hline Self employed & 4.00 & $2.06,7.74$ & 0.01 & 1.82 & $0.05,65.81$ & 0.74 \\
\hline Other & 2.11 & $1.20,3.69$ & 0.01 & 1.00 & & \\
\hline
\end{tabular}


TABLE 3: Continued.

\begin{tabular}{|c|c|c|c|c|c|c|}
\hline \multirow{2}{*}{ Variable } & \multicolumn{6}{|c|}{ Use of healthcare with NHIS } \\
\hline & Model 1 OR & $95 \% \mathrm{CI}$ & $p$ value & Model 2 AOR & $95 \% \mathrm{CI}$ & $p$ value \\
\hline \multicolumn{7}{|c|}{ Place of residence } \\
\hline Slum & 1.00 & & & 1.00 & & \\
\hline Zongo & 1.65 & $0.61,4.41$ & 0.31 & 10.32 & $1.24,85.94$ & 0.03 \\
\hline Old town & 1.61 & $0.67,3.88$ & 0.28 & 6.89 & $0.36,129.89$ & 0.05 \\
\hline Peri-urban & 3.20 & $1.13,9.07$ & 0.01 & 20.49 & $0.57,736.36$ & 0.05 \\
\hline Other & 2.75 & $0.24,30.51$ & 0.41 & 1.00 & & \\
\hline \multicolumn{7}{|c|}{ Use NHIS [active] } \\
\hline No & 1.00 & & & 1.00 & & \\
\hline Yes & 1.67 & $0.95,2.92$ & 0.05 & 2.19 & $1.18,4.07$ & 0.01 \\
\hline \multicolumn{7}{|c|}{ Ethnic background } \\
\hline Denkyira & 1.00 & & & 1.00 & & \\
\hline Other & 0.75 & $0.45,1.24$ & 0.27 & 0.38 & $0.10,1.46$ & 0.16 \\
\hline \multicolumn{7}{|l|}{ Religion } \\
\hline Christianity & 1.00 & & & 1.00 & & \\
\hline Islam & 0.80 & $0.45,1.45$ & 0.466 & 1.18 & $0.23,5.44$ & 0.82 \\
\hline
\end{tabular}

implication that, across different settings of Ghana, females especially those in their reproductive ages are more profound to enrol and renew their NHIS policy.

The age of individual household members influenced their decision to enrol and renew NHIS policy. The elderly people of age 58 years and above were less likely to have active membership to the NHIS though these groups frequently sought healthcare. This finding could be attributed to a number of factors including households financing sources for the scheme. For instance, the NHIS in Ghana has exemption for the aged 70 years and above. This exemption is an effort to cover the indigents otherwise classified as vulnerable including aged, children, pregnant women, and people with disabilities. However, the existing criteria peg exemption at 70 or more years and may have significant implication on payment sources for clients between 58 and 70 years. In Ghana, the compulsory retiring and retiring ages for the formal sector are 55 and 60 years, respectively. With the current exemption age pegged at 70 years and above, people who compulsorily retire from the public service may have to battle with the premium payment which invariably would restrict access to healthcare. Pension payments are so low that pensioners find it difficult to make ends meet let alone think about health expenditure. Individuals who are not resourced financially may not be able to enrol or renew their insurance policy. This is particularly true among elderly persons in the informal sector within the Upper Denkyira East Municipality who are predominantly peasant farmers with no regular pension scheme. This finding reinforces previous studies which suggest that the inability to pay for insurance premium constitutes the most frequently cited reason for limited enrolment $[43,44]$. However, the finding generally contradicts previous studies that examined the influence of age on NHIS policy ownership. In previous studies, enrolment and renewal of NHIS policy increase with age. Elderly people of about $60-70$ years and above have higher odds of enrolling and renewing into the scheme. Again, across people in the richest wealth quintile, the elderly population of 70 years and above have an increased odd of enrolling and renewing their NHIS. The differences in enrolment and renewal of NHIS among households in the current settings and those in previous studies could be attributed to the funding source to support enrolment.

The ethnic and religious affiliation of households plays a significant role in enrolling and renewing NHIS policy. The minority ethnic groups and Muslims were less likely to enrol and renew their NHIS policy. This finding could be explained by varying factors including limited funds, religious-cultural issues, and health seeking behaviour. This finding confirms previous evidence on the role of religion and ethnicity in determining enrolment and renewal of NHIS policy in Ghana. The role of religion in determining NHIS policy ownership varies according to geographical location and gendered identity. In the Upper West Region, previous finding showed that males who were Muslims were more likely to never enrol or drop out of their NHIS policy compared with Christians [25]. However, females who were Muslims had contrary exposure, where they were more likely to enrol and renew their NHIS policy compared with Christians [25]. Again, in some settings including Eastern and Central Regions of Ghana, individuals affiliated to a particular religion including Christianity, Muslim, and Tradition had higher odds of enrolling and renewing their NHIS policy $[29,31]$. The variation in enrolment into the scheme according to religious affiliation could be attributed to religious-cultural beliefs and health seeking behaviour. The argument surrounding this generally demonstrates that there is variation in the enrolment and renewal of NHIS policy according to religious affiliation. 
The study also found that the level of education consistently influenced households' decision to enrol and renew their NHIS policy. The odds of enrolling and renewing NHIS policy increased with the level of educational attainment. Individuals educated at secondary and tertiary level had higher odds of enrolling and renewing their NHIS policy. The finding implies that education plays a significant role in educating households about the important of enrolling and renewing NHIS policy. This finding confirms previous studies in Ghana [25, 27-29, 31] and other West Africa settings including Senegal and Mali [45]. Across these settings, individuals educated at the higher level, preferably secondary and tertiary education, were more profound to enrol and renew their NHIS policy [25, 27-29, 31]. However, individuals with low or no education are more likely to have never enrolled or possibly drop out of the scheme [25]. In some instances, the increased odds of enrolling and renewing NHIS policy further vary according to the wealth quintiles of the individuals. The increased policy enrolment among educated individuals could be linked to their basic understanding of the need to have financial risk protection. Again, in some instances, individuals that are educated at the higher level but fall within the lower wealth quintiles have higher odds of enrolling and renewing their NHIS policy compared with those in the wealthier quintile [29]. This demonstrates that, across different settings, education plays significant role in ensuring enrolment and renewal into NHIS policy. However, this could vary depending on the level and socioeconomic status of the individuals.

Limitation. The study was limited to only households in the Upper Denkyira East Municipality, without the perspectives of NHIS staff, health services providers, and health systems planners. Again, the study recruited a sample of 380 respondents across different communities to represent the entire municipality. In spite of these, the study employed several scientific scrutinies such as random sampling, pretesting of tools, informed consent processes, statistical analysis, and discussions of findings with relevant literature.

\section{Conclusion}

In this study, we examined the influence of households' profile on the use of NHIS and healthcare in the Upper Denkyira East Municipality. The factors influencing NHIS and use of healthcare were limited to only sociodemographic information compared with previous studies where management and health authorities' related factors are considered. Despite these, this study has provided insightful evidence to inform policy decision.

The study concludes that household's profile such as age, gender, income, education, and marital status influences individual's decision to renew their NHIS policy. Individuals who are married, females, and those with some educational credentials up to primary, secondary, and tertiary level were more likely to renew their NHIS policy. However, vulnerable population such as the elderly of 57-69 years and minority ethnic and religious groups including Muslims were less likely to renew their NHIS policy. The NHIS policy should revise the exemption bracket to wholly cover vulnerable groups such as minority ethnic and religious groups and elderly people at retiring age of 60 years. This would help to remove out-of-pocket payment for healthcare for these vulnerable populations.

\section{Data Availability}

The raw data (the administered questionnaires) informing the findings and conclusion of this article is freely available upon request from the authors and Institutional Review Board of KNUST. The raw data has been entered into STATA version 14 and right-protected with a password. All other materials such as copy of questionnaires and consent form are equally available upon request from the authors.

\section{Ethical Approval}

Ethical clearance was obtained from the Committee for Human Research Publication and Ethics at Kwame Nkrumah University of Science and Technology (KNUST) before the fieldwork. The researchers respected the rights of the respondents and ensured that informed consent was completed before the administration of the questionnaires. Again, a written permission was obtained from the Municipal NHIS Co-Coordinator and Health Directorate of Upper Denkyira East Municipal Assembly prior to the implementation of study methods.

\section{Disclosure}

This is to certify that this paper is a finding from original work. The authors have duly acknowledged the work(s) of others they used in writing this article/manuscript and have duly cited all such work(s) in the text as well as in the list of the references and they have presented within quotes all the original sentences and phrases.

\section{Conflicts of Interest}

The authors declare that they have no financial or personal relationships which may have inappropriately influenced them in writing this article.

\section{Authors' Contributions}

Eric Badu wrote the first draft of the manuscript. Eric Badu, Peter Agyei-Baffour, Isaac Ofori Acheampong, Kwasi AddaiDonkor, and Maxwell Preprah Opoku performed the data analysis and interpretation of results. All authors reviewed and made inputs into the intellectual content and agreed on its submission for publication.

\section{Acknowledgments}

The authors wish to thank the Municipal NHIS Authorities and Health Directorate of Upper Denkyira East Municipal Assembly. They again wish to thank the Committee on 
Human Research, Publications and Ethics, Kwame Nkrumah University of Science and Technology (KNUST), for approving the study protocol prior to its implementation. They are grateful to all the study participants for their support during the data collection.

\section{References}

[1] World Health Organization, World Health Statistics 2015, World Health Organization, 2015.

[2] S. Kwon, "Health care financing in Asia: Key issues and challenges," Asia-Pacific Journal of Public Health, vol. 23, no. 5, pp. 651-661, 2011.

[3] World Health Organization (WHO), Book Health System Financing: The Path to Universal Coverage, World Health Organization, 2010.

[4] S. Boyle, Health Systems in Transition: United Kingdom (England), WHO Regional Office for Europe on behalf of the European Observatory on Health Systems and Policies, Copenhagen, Denmark.

[5] E. Mossialos, M. Wenzl, R. Osborn, and C. Anderson, International Profiles of Health Care Systems, The Commonwealth Fund, 2016.

[6] G. Carrin, M.-P. Waelkens, and B. Criel, "Community-based health insurance in developing countries: A study of its contribution to the performance of health financing systems," Tropical Medicine \& International Health, vol. 10, no. 8, pp. 799-811, 2005.

[7] UNICEF, National Health Insurance in Asia And Africa: Advancing Equitable Social Health Protection to Achieve Universal Health Coverage, United Nations Children's Fund, New York, NY, USA, 2012.

[8] B. Garshong and J. Akazili, Universal Health Coverage Assessment, Global Network for Health Equity (GNHE), 2015.

[9] D. A. Adewole, M. Dairo, and O. Bolarinwa, "Awareness and Coverage of the National Health Insurance Scheme among Formal Sector Workers in Ilorin, Nigeria," African Journal of Biomedical Research, vol. 19, pp. 1-10, 2016.

[10] E. F. Adebayo, O. A. Uthman, C. S. Wiysonge, E. A. Stern, K. T. Lamont, and J. E. Ataguba, "A systematic review of factors that affect uptake of community-based health insurance in lowincome and middle-income countries," BMC Health Services Research, vol. 15, no. 1, article no. 543, 2015.

[11] J. Mensah, J. R. Oppong, and C. M. Schmidt, "Ghana's national health insurance scheme in the context of the health MDGs: an empirical evaluation using propensity score matching," Health Economics, vol. 19, no. 1, pp. 95-106, 2010.

[12] N. J. Blanchet, G. Fink, and I. Osei-Akoto, "The effect of Ghana's National Health Insurance Scheme on health care utilisation," Ghana Medical Journal, vol. 46, no. 2, pp. 76-84, 2012.

[13] J. P. Jütting, "Do community-based health insurance schemes improve poor people's access to health care? Evidence from rural senegal," World Development, vol. 32, no. 2, pp. 273-288, 2004.

[14] A. Creese, S. Bennett, G. Schieber, and A. Maeda, "Rural risksharing strategies," World Bank Discussion Papers, pp. 163-182, 1997.

[15] D. M. Dror and C. Jacquier, "Micro-insurance: Extending Health Insurance to the Excluded," International Social Security Review, vol. 52, no. 1, pp. 71-97, 1999.
[16] B. Ekman, "Community-based health insurance in low-income countries: A systematic review of the evidence," Health Policy and Planning, vol. 19, no. 5, pp. 249-270, 2004.

[17] S. Witter and B. Garshong, "Something old or something new? Social health insurance in Ghana," BMC International Health and Human Rights, vol. 9, no. 1, article 20, 2009.

[18] J. Akazili, B. Garshong, M. Aikins, J. Gyapong, and D. McIntyre, "Progressivity of health care financing and incidence of service benefits in Ghana," Health Policy and Planning, vol. 27, no. 1, pp. i13-i22, 2012.

[19] National Health Insurance Authority, National Health Insurance Authority, NHIA, 2013.

[20] National Health Insurance Authority, National Health Insurance Scheme, National Health Insurance Authority, 2015.

[21] M. Jowett, A. Deolalikar, and P. Martinsson, "Health insurance and treatment seeking behaviour: Evidence from a low-income country," Health Economics, vol. 13, no. 9, pp. 845-857, 2004.

[22] E. K. Ansah, S. Narh-Bana, S. Asiamah et al., "Effect of removing direct payment for health care on utilisation and health outcomes in Ghanaian children: A randomised controlled trial," PLoS Medicine, vol. 6, no. 1, Article ID e1000007, pp. 0048-0058, 2009.

[23] C. M. Schmidt, J. H. Mensah, and J. R. Oppong, “Ghana’s national health insurance scheme in the context of the health MDGs-an empirical evaluation using propensity score matching," Ruhr Economic Paper, 2009.

[24] J. Dixon, E. Y. Tenkorang, I. N. Luginaah, V. Z. Kuuire, and G. O. Boateng, "National health insurance scheme enrolment and antenatal care among women in ghana: is there any relationship?" Tropical Medicine \& International Health, vol. 19, no. 1, pp. 98-106, 2014.

[25] J. Dixon, I. Luginaah, and P. Mkandawire, "The National Health Insurance Scheme in Ghana's Upper West Region: A gendered perspective of insurance acquisition in a resource-poor setting," Social Science \& Medicine, vol. 122, pp. 103-112, 2014.

[26] A. S. Preker and G. Carrin, Health Financing for Poor People: Resource Mobilization And Risk Sharing, World Bank Publications, 2004.

[27] K. A. Alatinga and J. J. Williams, “Towards Universal Health Coverage: Exploring the Determinants of Household Enrolment into National Health Insurance in the Kassena Nankana District, Ghana," Ghana Journal of Development Studies, vol. 12, no. 1-2, p. 88, 2015.

[28] S. Manortey, J. Vanderslice, S. Alder et al., "Spatial analysis of factors associated with household subscription to the National Health Insurance Scheme in rural Ghana," Journal of Public Health in Africa, vol. 5, no. 1, pp. 1-8, 2014.

[29] C. Jehu-Appiah, G. Aryeetey, E. Spaan, T. de Hoop, I. Agyepong, and R. Baltussen, "Equity aspects of the national health insurance scheme in Ghana: who is enrolling, who is not and why?" Social Science \& Medicine, vol. 72, no. 2, pp. 157-165, 2011.

[30] S. Chankova, S. Sulzbach, L. Hatt et al., An Evaluation of The Effects of The National Health Insurance Scheme in Ghana, Abt Associates Inc, Bethesda, MD, USA, 2009.

[31] C. Jehu-Appiah, G. Aryeetey, I. Agyepong, E. Spaan, and R. Baltussen, "Household perceptions and their implications for enrolment in the National Health Insurance Scheme in Ghana," Health Policy and Planning, vol. 27, no. 3, pp. 222-233, 2011.

[32] S. Manortey, S. Alder, B. Crookston, T. Dickerson, J. VanDerslice, and S. Benson, "Social deterministic factors to participation in the National Health Insurance Scheme in the context of 
rural Ghanaian setting," Journal of Public Health in Africa, vol. 5, no. 1, pp. 1-18, 2014.

[33] S. Antwi, X. Zhao, E. K. Boadi, and E. O. Koranteng, "SocioEconomic Predictors of Health Insurance Claims: Evidence from Ghana," International Journal of Economics and Finance, vol. 6, no. 3, 2014.

[34] D. Boateng and D. Awunyor-Vitor, "Health insurance in Ghana: Evaluation of policy holders' perceptions and factors influencing policy renewal in the Volta region," International Journal for Equity in Health, vol. 12, no. 1, article no. 50, 2013.

[35] H. Amu and K. S. Dickson, "Health insurance subscription among women in reproductive age in Ghana: do sociodemographics matter?" Health Economics Review (HER), vol. 6, article 24, 2016.

[36] D. Parmar, G. Williams, F. Dkhimi et al., "Enrolment of older people in social health protection programs in West Africa Does social exclusion play a part?" Social Science \& Medicine, vol. 119, pp. 36-44, 2014.

[37] S. Antwi, X. Zhao, and E. O. Koranteng, "Gender disparities in ghana national health insurance claims: an econometric analysis," International Journal of Business and Social Research, vol. 4, pp. 70-81, 2014.

[38] Upper Denkyira Municipal, Municipal profile, Ministry of Local Governance \& Rural Development, 2013.

[39] W. G. Cochran, Sampling Techniques, John Wiley \& Sons, 2007.

[40] L. Naing, T. Winn, and B. Rusli, "Practical issues in calculating the sample size for prevalence studies," Archives of Orofacial Sciences, vol. 1, pp. 9-14, 2006.

[41] Ghana Statistical Service [GSS], 2010 Population and Housing Census, Ghana Statistical Services, 2012.

[42] "Government announces increment in minimum wage/salaries for public workers," http://www.ghana.gov.gh/index.php/ media-center/news/2023-\%09government-announces-increment-in-minimum-wage-salaries-for-public-workers.

[43] S. Sulzbach, B. Garshong, and G. Owusu-Banahene, "Evaluating the effects of the national health insurance act in ghana: baseline report," Partners for Health Reformplus, 2005.

[44] F. P. Diop, "Determinants of financial stability of mutual health organizations in the thies region of senegal: household survey component," Partners for Health Reformplus, 2006.

[45] S. Chankova, S. Sulzbach, and F. Diop, "Impact of mutual health organizations: evidence from West Africa," Health Policy and Planning, vol. 23, no. 4, pp. 264-276, 2008. 


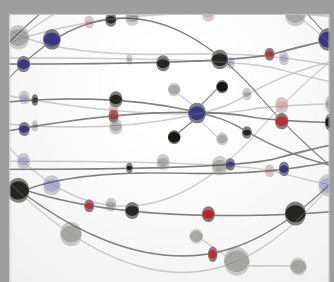

The Scientific World Journal
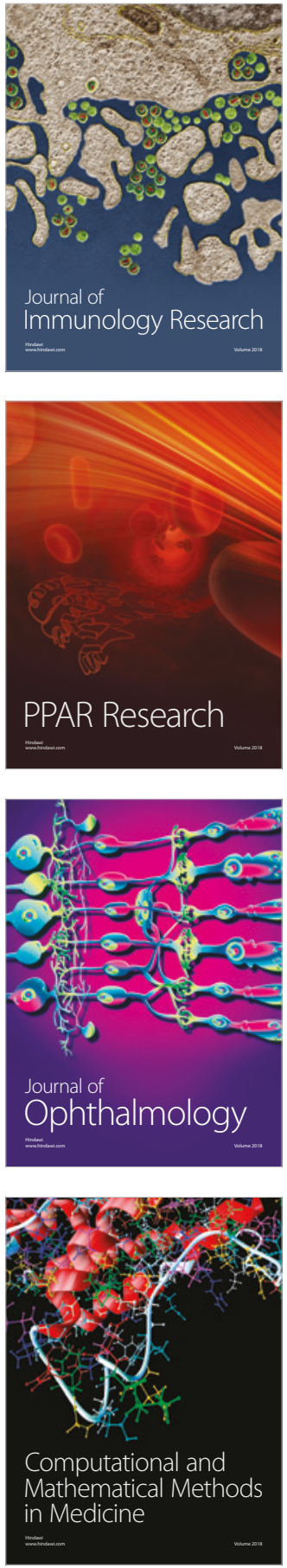

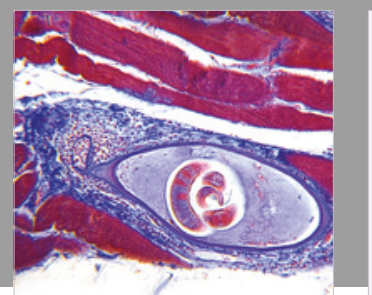

Gastroenterology Research and Practice

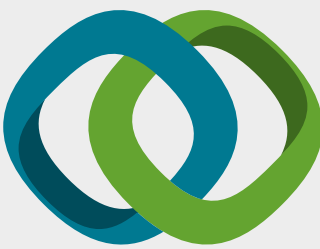

\section{Hindawi}

Submit your manuscripts at

www.hindawi.com
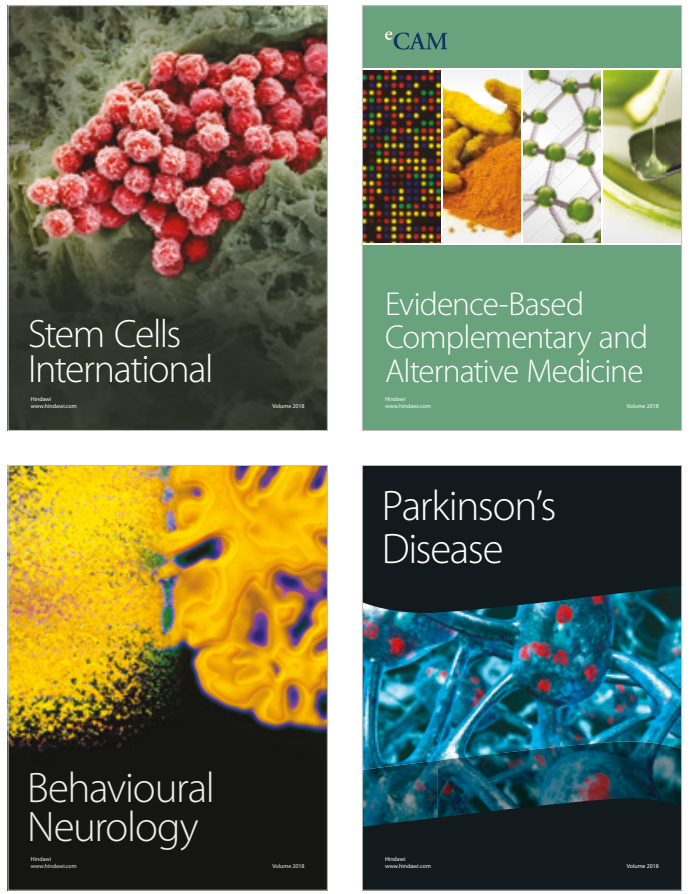

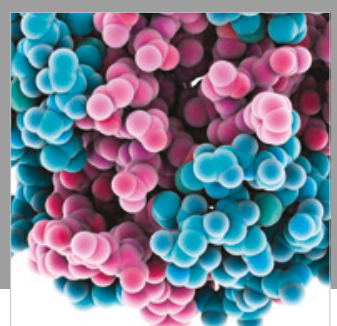

ournal of

Diabetes Research

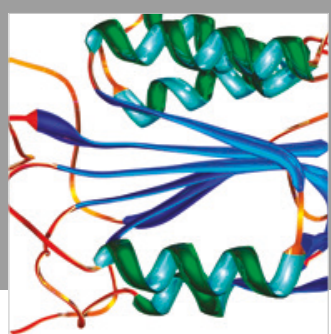

Disease Markers
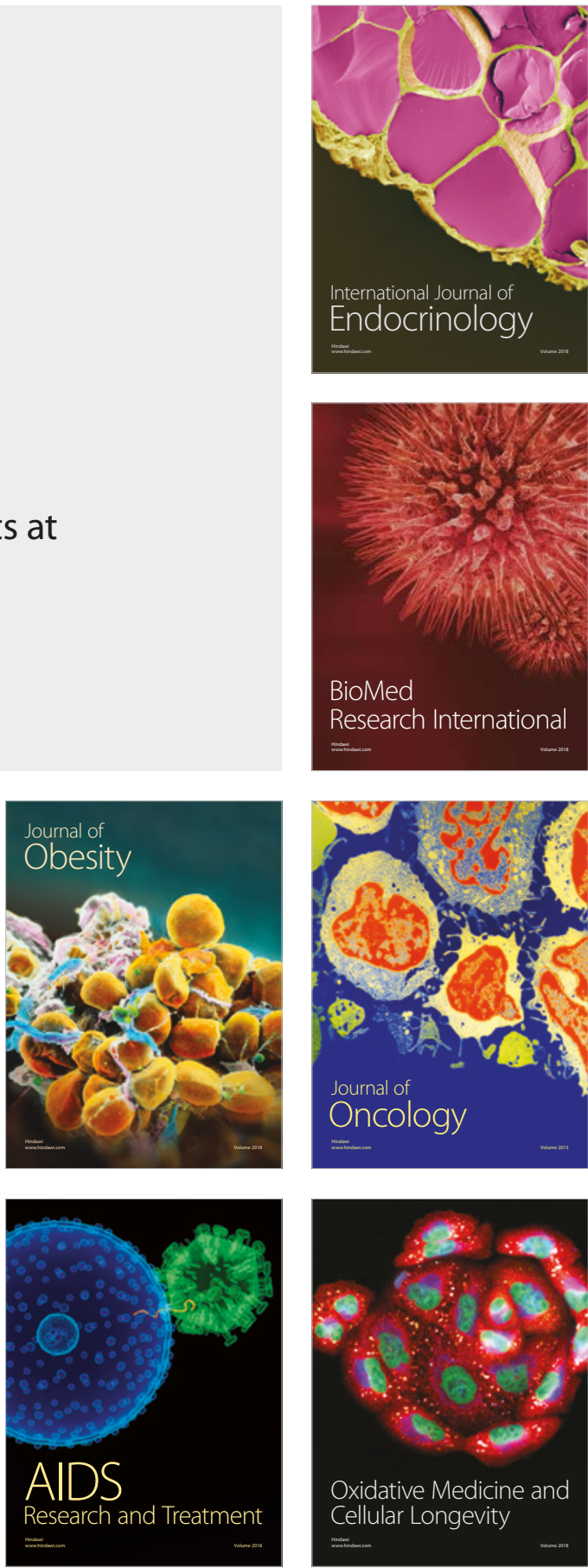